\title{
The New Sensing Fibre for Application in Optical Fibre Current Sensor
}

\author{
K. BarczaK ${ }^{a, *}$, T. Pustelny ${ }^{a}$, D. Dorosz ${ }^{b}$ And J. Dorosz ${ }^{b}$ \\ ${ }^{a}$ Institute of Physics, Silesian University of Technology \\ Krzywoustego 2, 44-100 Gliwice, Poland \\ ${ }^{b}$ Department of Optical Radiation, Białystok Technical University \\ Wiejska 45, 15-950 Białystok, Poland
}

\begin{abstract}
The present paper deals with investigations concerning optical fibre current sensors. They are mainly applied in measurements of the intensity of the electric current in the power lines as so-called optical transformers of the electrical current. The most important advantages of fibre current sensors are: safety of service, insulating power as well as their insensitiveness to electromagnetic interference. The investigations were concentrated on designing of adequate sensing fibre, and particularly on the choice of an adequate kind of glass, of which this fibre could be made. Besides, also the head of the fibre current sensor was designed, basing on the suggested and produced sensing fibre. The paper presents the results of magneto-optic tests of the glass and the sensing fibre.
\end{abstract}

PACS numbers: 78.20.Ls, 42.81.Gs, 42.81.Pa, 42.81.Qb, 42.81.Gs

\section{Introduction}

In electric power engineering a growing demand for optical fibre current sensors is to be observed. One of the domains of interest is the measurement of the current in the transmission lines. Traditionally so-called current transformers are applied, constituting elements of the system of protection, and basing on the phenomenon of electromagnetic induction. These are big elements, dangerous in practical application, and as they do not warrant any galvanic insulation, the hazard arises of electric shocks as well as of the destruction of other appliances installed in the system.

The optoelectric transformer of electrical current is void of these drawbacks. It is absolutely safe and isolated from the high-voltage line. Failures of the optoelectric transformer of instantaneous switching off the current do not involve any

*corresponding author; e-mail: kamil.barczak@polsl.pl 
danger and electromagnetic noise and disturbances [1-3]. Optoelectric transducers with optical fibres serving as a sensor operate basing on the so-called Faraday effect. This is a phenomenon in which the plane of the polarisation of light rotates in the presence of the magnetic field resulting from the electric current passing through the high-voltage line. Therefore, a change of the state of light polarisation caused by other external agents is undesirable. Such a fundamental parasitical effect is the formation of optical birefringence of the fibre due to their deformation (bending and compression) occurring during the production of the fibre (elasto-optical effect) $[2,4]$. The aim of the presently accomplished investigations is to obtain a fibre with a good magneto-optical sensitivity, and a low elasto-optic constant, and also to construct the head of the current indicator basing on this kind of fibre.

\section{The new optical fiber}

The structural assumption was to achieve a kind of fibre with a high value of the Verdet constant, a low elasto-optic constant. For this purpose multicomponent glass was made with a possibly high value of the refractive index, thanks to a high percentage of lead oxides $\mathrm{PbO}$. The achieved value of the refractive index amounted to $n=1.619$. The glass was constructed in such a way that in the course of its production the internal stresses might be put down to a minimum $[3,2]$.

The first obtained fibres have the length of the cut-off wave amounting to $633 \mathrm{~nm}$, the difference between the refractive indices $\Delta n=0.0005$, the diameter of the core $12 \mu \mathrm{m}$, the diameter of the jacket cladding $150 \mu \mathrm{m}$, the numerical aperture $\mathrm{NA}=0.04$ and an attenuation of $0.1 \mathrm{~dB} / \mathrm{m}[4]$.

\section{Results of measurements}

The glass prepared for the requirement of the optical fibre technology has also been the subject of investigations. Among others, its Verdet constant for a wavelength of $660 \mathrm{~nm}$ was determined. This constant amounts to $V=10.57 \mathrm{rad} /(\mathrm{T} \mathrm{m})$. This $V$ value is similar to the $V$ of light flint glass and it is twice higher than for silica glass, which is simultaneously a glassy matrix of the investigated glass.

The obtained fibres were tested on a test stand for measurements of magneto-optic effects [5-8] (Fig. 1) at a constant magnetic field. The source of the magnetic field was a coil with an air core, $0.8 \mathrm{~m}$ long.

The tests were carried out for a wavelength of $660 \mathrm{~nm}$. The results of these measurements have been gathered in Fig. 2 and Fig. 3. Noticeable is the excellent linearity of the characteristics. Slight changes of the ellipticity angle (Fig. 3) indicate inconsiderable internal stresses of the fibre, inducing a linear birefringence. In the case of the measurements quoted above the sensitivity of the fibre to the external magnetic field amounted to $1.95 \mathrm{rad} /(\mathrm{T} \mathrm{m})$.

Due to the varying low numerical aperture $(\mathrm{NA}=0.04)$ it is rather difficult to introduce the light correctly into the fibre and to eliminate the cover modes. The 


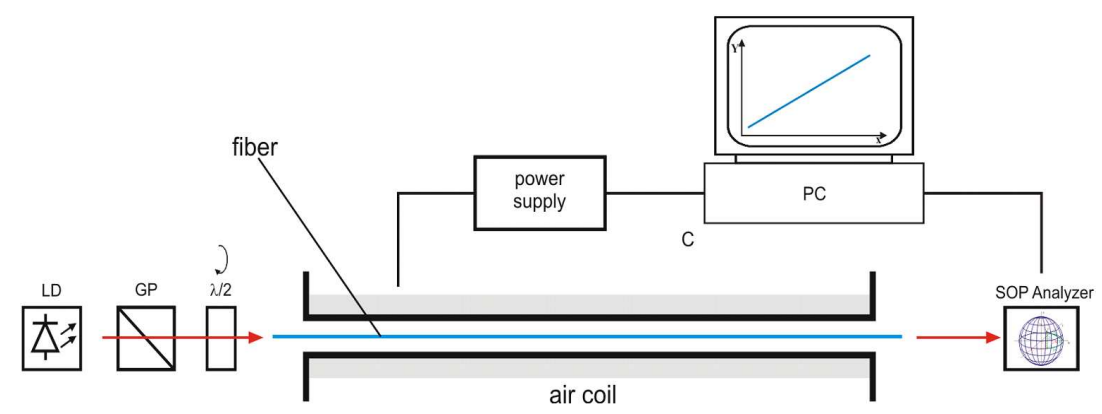

Fig. 1. Scheme of the measurement stand.

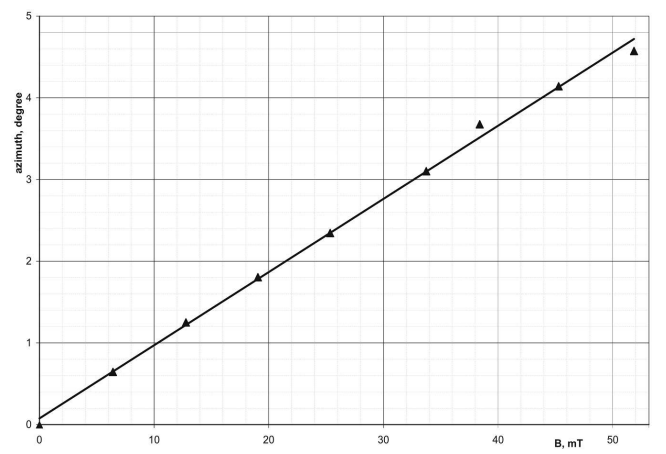

Fig. 2. Results of azimuth of the polarisation state at the end of the sensing fibre as a function of magnetic field induction.

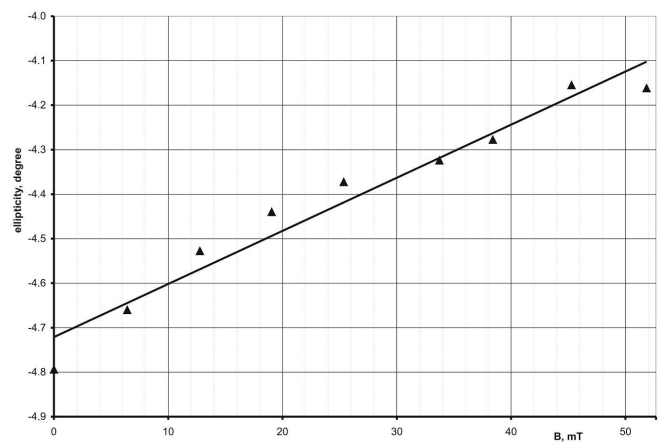

Fig. 3. Results of ellipticity of the polarisation state at the end of the sensing fibre as a function of magnetic field induction.

tested fibre had a length of about $1.1 \mathrm{~m}$ which also impeded the elimination of the cladding and cover modes by their attenuation and emission. The application of a striper of the modes is in this case inadmissible because it would cause considerable stresses as well as accidental changes of polarisation. Thus, only a small state of polarisation of living light was to be observed ( DOP $=42 \%$ ). 


\section{Conclusions}

The results presented in Fig. 2 and Fig. 3 are rather promising. The next stage of investigations will comprise the preparation of a fibre with a higher numerical aperture and a larger diameter of the core with the standard $125 \mu$ m cladding. Anticipated are also processes of secondary soaking of the fibres in order to reduce the internal stresses. The fibre prepared in such a way will then be used in the construction of the head of the current sensor (Fig. 4) illustrates the designed diagram of the current sensor for the fibre dealt with in this paper [5].

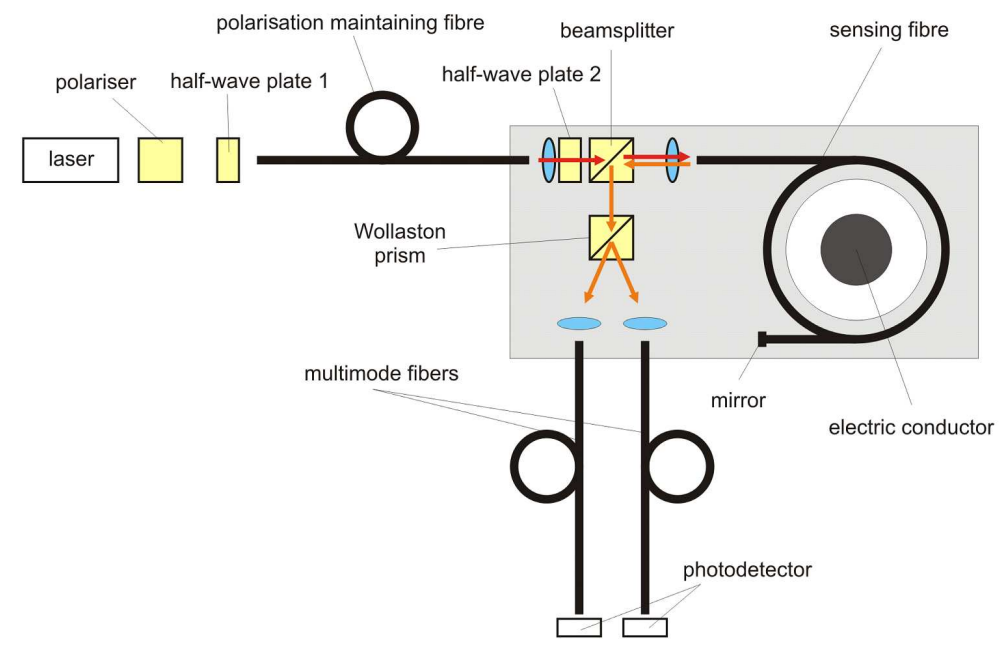

Fig. 4. Scheme of the optical fibre current sensor.

\section{Acknowledgments}

The work was sponsored by the State Committee for Scientific Research within the grant N N515 409534.

\section{References}

[1] K. Kurosawa, in: Proc. 11th OFS Conf., Advanced Sensing Photonics, Japan Society of Applied Physics, 1996, p. 134.

[2] T. Yamashita, A. Watabe, I. Masuda, K. Sakamoto, in Ref. [1], p. 168.

[3] D. Dorosz, J. Świderski, A. Zając, M. Reben, in: Proc. XXI Int. Congress on Glass, Strasbourg 2007, p. 147.

[4] J. Dorosz, Polski Biuletyn Ceramiczny, Ceramika 86, 115 (2005) (in Polish).

[5] T. Pustelny, K. Barczak, J. Wójcik, K. Gut, Opt. Appl. XXXIV, 531 (2004).

[6] K. Barczak, T. Pustelny, Proc. SPIE 5956, M1 (2005).

[7] K. Barczak, T. Pustelny, A. Szpakowski, M. Błahut, J. Phys. IV (France) 129, 85 (2005).

[8] K. Barczak, T. Pustelny, J. Phys. IV (France) 137, 15 (2006). 